\title{
EXISTENCE OF MILD SOLUTIONS FOR FRACTIONAL DIFFERENTIAL EQUATIONS IN SEPARABLE BANACH SPACE
}

\author{
ADEL JAWAHDOU
}

Abstract. This paper is concerned with the existence of mild solutions for fractional semilinear differential equations with non local conditions in separable Banach spaces. The result is established by using the technique of measures of noncompactness in Banach spaces of continuous functions and Schauder fixed point theorem.

Mathematics subject classification (2010): 34G20, 35R10.

Keywords and phrases: semilinear differential equations, measure of noncompactness, mild solutions, Schauder fixed point theorem.

\section{REFERENCES}

[1] J. Banas, K. Goebel, Measure of Noncompactness in Banach Spaces, Lect. Notes Pure Appl. Math., vol.60, Marcel Dekker, New York, 1980.

[2] L. Byszewski, Theorems about the existence and uniqueness of solutions of a semilinear evolution nonlocal Cauchy problem, Appl. Anal 40 (1991), 173-180.

[3] T. Diagana, G. M. Mophou, M. N'Guerekata, On the existence of mild solutions to some semilinear fractional integrodifferential equations, Electron. J. Qual. Theory Differ. Equ., 58 (2010), 1-17.

[4] Z. Fan, G. Li, Existence results for semilinear differential equations with nonlocal and implusive conditions, J. Funct. Anal. 258 (2010), 1709-1727.

[5] H. Gu, J.J. Trujillo, Existence of mild solution for evolution equation with Hilfer fractional derivative, Applied Mathematics and Computation, No 257 (2015), 344-354.

[6] H.P. Heinz, On behaviour of measures of noncompactness with respect to differentiation and integration of vector-valued functions, Nonlinear Anal., No 7 (1983), 1351-1371.

[7] A. Jawahdou, Mild solutions of functional semilinear evolution Volterra integrodifferential equations on an unbounded interval, Nonlinear Anal., 74, No 18 (2011), 7325-7332.

[8] A. Jawahdou, Mild Solutions of Fractional Semilinear Integro-Differential Equations on an Unbounded Interval, Appl.Math., 4, No 7 (2013), 34-39.

[9] A.A. Kilbas, H.M. Srivastava, J.J. Trujillo, Theory and Applications of Fractional Differential Equations, in: North-Holland Mathematics Studies, vol.204, Elsevier Science B.V., Amsterdam, 2006.

[10] S. Ji, G. Li, Solutions to nonlocal fractional differential equations using a noncompact semigroup, Electronic Journal of Differential Equations. Vol. 2013 (2013), No. 240, 1-14.

[11] Y. Lin, J. Liu, Semilinear integrodifferential equations with nonlocal Cauchy problem, Nonlinear Anal. 26 (1996), 1023-1033.

[12] L. Olszowy, Existence of Mild Solutions for Semilinear Nonlocal Cauchy Problems in Separable Banach Spaces, Z. Anal. Anwend., 32, No 2 (2013), 215-232.

[13] L. Olszowy, S. Wẹdrychowicz, Mild solutions of semilinear evolution equation on an unbounded interval and their applications, Nonlinear Anal., 72, No 3.4 (2010), 2119-2126.

[14] S. Ntouyas, P. Tsamatos, Global existence for semilinear evolution equations with nonlocal conditions, J. Math. Anal. Appl. 210 (1997) 679-687.

[15] I. Podlubny; Fractional Differential Equations, Academic Press, New York (1999).

[16] J.R. Wang, A.G. Ibrahim, M. Feckan, Nonlocal Cauchy problems for semilinear differential inclusions with fractional order in Banach spaces, Communications in Nonlinear Science and Numerical Simulation, No 27(1-3), (2015), 281-293. 
[17] J.R. Wang, Y. Zhou, M. Feckan, On the nonlocal Cauchy problem for semilinear fractional order evolution equations, Central European Journal of Mathematics, 12(6), (2014), 911-922.

[18] J.R. Wang, Y.Z. Hou, Existence of mild solutions for fractional delay evolution systems, Applied Mathematics and Computation, 218 (2011) 357-367.

[19] F. Xianlong, E. Khalil, Existence of solutions of a semilinear functional-differential evolution equations with nonlocal conditions, Nonlinear Anal. 54 (2003), 215-227.

[20] X. Xue, Semilinear nonlocal differential equations with measure of noncompactness in Banach spaces, J. Nanjing. Univ. Math., 24 (2007), 264-276.

[21] X. Xue, M. Xing, Existence of semilinear differential equations with nonlocal initial conditions, Acta. Math. Sini., 23(2007), 983-988.

[22] Y. Zhou, F. Jiao, Existence of mild solutions for fractional neutral evolution equations, Comput. Math. Appl., 59 (2010), 1063-1077. 